\title{
Interoperability in IOT based smart home: A review
}

\author{
Summia Taj, Uniza Asad, Moeen Azhar, Sumaira Kausar* \\ Bahria University, Islamabad 46000, Pakistan \\ Corresponding Author Email: sumairakausar@bui.edu.pk
}

https://doi.org/10.18280/rces.050302

Received: 6 August 2018

Accepted: 26 September 2018

\section{Keywords:}

heterogeneous, iot, interoperability, feature, middleware

technologies,smarthomes, sensing

\begin{abstract}
The IOT Internet of things is rapidly moving towards reality. It is broadly applied to plenty of areas which includes healthcare, smart homes, smart cities, energy management, logistics and to forth. Smart homes are distinct class of IOT environments with a variety of connected heterogeneous devices. Daily life entities connected to the internet are enriched with the capabilities of identifying, sensing and processing. The heterogeneous entities require to execute mutual performance of activities effectively \& rapidly. However, with the huge growth of connected devices, the ability of interoperation among devices is going to be a challenge. In this paper a state of the art on interoperability in smart homes is presented. The detailed discussion is given on numerous feature of connectivity protocols used for interoperation, limitation of existing solutions encounters in research.
\end{abstract}

\section{INTRODUCTION}

The IOT (Internet of Things) paradigm will be a fact swiftly due to plenty of systemized endeavors. In IOT paradigm entities in daily life linked to the internet are enriched with the capabilities of identifying, sensing and processing [1-2]. Kevin Ashton originally proposed the concept of IoT as distinct recognizable interoperable objects by using RFID Radio frequency identification technology in 1999. The core traits of IOT are Connectivity, objects, data, transmission, brilliance, process and ecosystem as illustrated in fig 1 . Though, the particular definition of IoT is quiet subjective to the considered viewpoints [11-13].

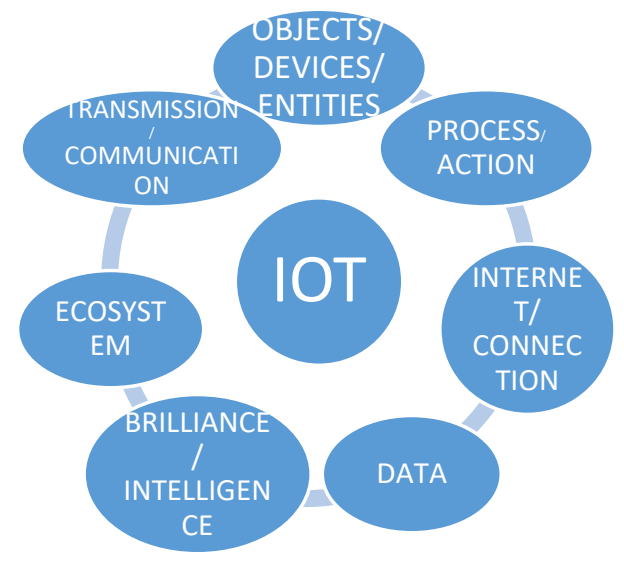

Figure 1. Basic layout of IOT infrastructure

IOT is considered as dispersed heterogeneous model of allied things which delivers services found on using and merging data obtained by diverse things. Typically, it has abilities to sense the data from environment, obtaining physiological measurements, identifying objects and events in the surroundings and the ability to process this information and communicate within the connected components [3]. It may have capability to transform the received data into instruction which utilized feedback to other things decreasing human interference $[4,24]$. It is internetworking of substantial devices grounded on standard communication architecture utilized in everyday life to offer new services to the users [5].

IOT is broadly applied in numerous areas [6] such as healthcare [8, 35], energy [9, 25], wider scope of community home [31], city and country [7, 27] as well as logistics [10] [26] as shown in fig 2.

A smart home is a collaborative collection of devices and subsystems. The subsystems are comprising of security cameras \& alarms, fire alarms, energy management employments, and so ahead [37]. Things/isolated devices in daily life such as a washing machine, refrigerator and all home appliances connected to the internet and distantly coordinated. Hence numerous advancement [28] there comes many exploration confronts that have been notorious in IOT. Among them highly important are Energy consumption, Trust [34], Privacy \& security, Standardization [32], Heterogeneous resources [29], Freshness of data [32] and the most emerging issue Interoperability [18-19, 28]. It is predicted that the future Internet will contain tens of billions of smart devices by 2020 $[7,20]$. The massive advancement in the connected devices to the internet developing a massive variety of challenges [14, 29].

Interoperability is gone to be a key challenge for IOT's prompt progress. This can be primarily attributed to the existence of a number of diverse set of technologies both old and new. Interoperability is critical in IOT as most of the communication is machine to machine (M2M) [21-23]. The IOT perception along with smart metering has latent to change the smart homes into energy aware milieus. So the more ecosystems and devices are interconnected the more interoperability issue will arise [36]. Numerous IOT applications can be acknowledged in each sphere and continuously evolving new on regularly basis, there need a 
strong interoperability among things/devices. Interoperability additionally concerns several traits such as security and privacy, standardization, etc. [15-17].

We are inspired to summarize the research progress attained so far in the development, and standardization of IOT enabling technologies as well as intended to find the key challenges in interoperability of IOT and a deep sight into user interoperability of heterogeneous devices in the smart homes infrastructure, besides it brief discussion of different approaches to solve the interoperability issue among devices [29] will be discussed, and to identify critical research topics and future research directions of IOT.

\section{LITERATURE REVIEW}

\subsection{Basic connectivity interoperability}

To connect and communicate different devices to each other or to the internet wireless home automation networks (WHANs) are being used in the smart homes. The authors [38] used the $\mathrm{z}$-wave protocol for connectivity and to solve the interoperability in smart homes. They present a Z-wave based device classification i.e, master and slave devices, its architecture containing four layers i.e., Application, Routing, $\mathrm{MAC}$, and the transfer, and simulation of protocol on door lock and light switches inside the smart homes.

S. COURREGES [52] established the idea of Radio Frequency (RF) use with Bluetooth and other protocols to increase the performance of Interoperability, ERDF will be connected to RF to minimize the energy rate, ZigBee $2.4 \mathrm{GHz}$ will combine with RF for exchanging of rates and stores in cloud computing

In paper [56] they discussed home automation system based on mobile cells, as there are various chances of network problem and there will be possibility we may not receive the information of sensors and nodes, so to avoid these failures they introduced SOA smart-home environment based system Open Services Gateway Initiative (OSGi) and mobile-agent (MA) technology. It establishes the secure network between server and client with the help of session protocol. MA resolves the failure problem and cleared the unwanted data.

\subsection{Network interoperability}

A novel architecture for smart home proposed in [39] based on RNS recourse name services by using IOT identifiers to cater for the heterogeneity. The RNS describes the contributing consumers of smart homes and affiliation amongst and develop the certain methods of smart home services to achieve the better scalability and interoperability among appliances. The authors [40] presented a framework for interoperability to aid the vertical solutions in multifunction domotic applications which includes the security, comfort and energy. The LabVIEW software is used to analyze the framework. The virtual emulated and real time commercial devices used to develop the system. OpenWebNet protocol is used for speedy home automation letting test configuration.

Jahoon Koo et.al [42] presented a mechanism IoT DNS (Device Name System), which use to infer and interprets the device ID concerning heterogeneous platforms. Additionally, they gave a brief comparison of the current Device ID systems widely used in different IOT platforms (i.e., oneM2M, GS1 'Oliot', IBM 'Watson IoT', and OCF 'IoTivity').
Moataz Soliman [49] used Zigbee, low power wireless technology to coordinate with home appliances and JSON for exchanging data between resident and devices such as washing machines, Air conditioner and Freezers to stop and start the appliances. By Zigbee coordinator they receive the current status of appliances and JSON send the data to resident and stores data in Cloud then Zigbee node sends the data to final destination. The Zigbee used for communication is IEEE 802.15.4.

In paper [51] they have used IOT devices which cannot be understandable, make them trans able for Interoperability so they can be further use for heterogeneous podium, for this they used IOT device named device identification (ID) which has raw data, so to convert raw data in to useful data they introduced the concept of Machine 2 Machine translator (M2M). M2M needs OID (Object Identifier) to identify the format and data stored in ID then oneM2M translator will change format of ID and store it as metadata.

In paper [53] they used the WSN (Wireless Sensor Network) with AAL (Ambient Assisted Living), so that the resident can live freely and control the power with remotes. They use IPv6 protocol with WSN as WSN is low voltage so IPv6 works best with it and make the model more heterogeneous. The IPv6 protocol addresses each node and send address directly to remote, the residents can easily configure and monitors the node. WSN will keep updating each sensor and the bandwidth of each node will be very high.

In paper [54] authors introduced the concept of networking, how home appliances and electronics can be monitored and controlled by remotes, laptops, mobile etc. For this they composed the Universal Plug and Play (UPnP) architecture, it uses different type of protocols and layers due to which it is multi-tasking and can handle multiple home electronics and appliances simultaneously. It uses "TCP/IP protocol, Internet Protocol (IP), Transmission Control Protocol (TCP), User Datagram Protocol (UDP), Hyper Text Transport Protocol (HTTP), Simple Object Access Protocol (SOAP), Extensible Markup Language (XML), and General Event Notification Architecture (GENA)" due to which UPnP updates and install drivers and updates automatically.

In paper [58] the authors discussed the Interoperability problem between two devices and how they can be solved, for this the availability, accessibility of device is very important. IPv6 protocol is used for this purpose if two devices are different they will tell the user about heterogeneous devices and do semantic transformation.

In paper [60] they focused to keep the home application heterogeneous within the given framework. Ethernet used for connectivity in home application and SOAP protocol for exchanging of messages with XMLP within the given framework.

\subsection{Syntactic interoperability}

Andreas k. etal [41] proposed an architecture for smart homes applications of Web Of Things (WoT) and validate their study by using case studies. WoT was offered for the interoperability among the mounting ecosystem internet supported devices by utilizing web principles. Some of the major issues were argued i.e., interoperability of heterogeneous devices in smart homes by using web techniques, energy saving mechanisms, real time response employ to energy awareness. In the article [43] authors proposed a novel intelligent interoperability framework aimed 
at smart homes. The proposed methodology grounded on SOAP simple object Access Protocol which aims to offer platform for heterogeneous devices for interoperation. The proposed framework instigated interoperation in numerous home devices to validate the effectiveness and tested in LAN. In [44] the authors presented a new idea to interconnection among heterogeneous devices using a gateway CoAP and protocol (the Propriety FS20) for smart home.

The authors [45] offered a mechanism grounded on the code generative and ontology alignment techniques to meet the interoperability among the devices and services. An Ontology is generated for each device type according to the meta model and then ontology alignment techniques applied to validate the semi automatic perceived communication among parallel devices. Authentication of alignment is done by an expert and classification based on pattern recognition techniques. They used UPnP plug and play protocol and testing is done on HP4515x printer.

The proposed approach [47] consist of Zigbee and UPnP Network Bridge to avoid the drawback of UPnP [66]. Zigbee protocol is used to associating UPnP due to its low consumption in term of energy. Seamless network bridge instigated to assist the interoperability UPnp-Zigbee network in smart homes. The authors proposed [46] a novel OHNet object based home network which works as a bridge aiding the devices using diverse protocols. The proposed method is emulated on several smart home smart grid devices and depicts that it can control such devices. In [48] Simple Object Access Protocol (SOAP) based architecture aided with web services delivering interoperation and scalability for tackling heterogeneous systems.

In paper [50] authors try to improve the semantic Interoperability when they work with heterogeneous IOT devices and makes the hardware and software devices more flexible. Doctor records, checks and maintains all the data of patient, for this doctor doesn't need any vendor device, the method imposed on this paper is that doctor works on three domains 1. User Interface 2. Cloud Computing 3. Semantic Interoperability. SI made all the raw data in to useful meaning and UI helps to collect the data from different IOT devices with SI and clouding system is storing all data, so whenever doctor wants can check the previous record of patient. In this paper authors used RFD for exchanging data raw data in meaningless information.

In paper [52] authors discuss the four requirements for any architecture for smart homes i.e. interoperability, addressability, compatibility, scalability, to maintain these requirements they introduced HEPA with Hexagonal architecture because of its high Interoperability. Each party have adaptors and ports to connect with IOT devices but each company's devices have its own adaptor if third company's devices wants to access with devices by any other company they will use communication protocol and REST protocol will shorten the steps for connectivity.

In paper [55] authors proposed the solution to overcome the barriers and noise in data for this they introduced the node called Interworking Proxy Entity (IPE) works with M2M architecture for conversion of data for which $\mathrm{Z}$ Wave is used with XML to describe the format of data omeM2m is used with these two protocols to provide the proper platform for data conversion.

In paper [57] they proposed the model based on Home Automation System for controlling of lights specially daylight lights. For this they used Zigbee Protocol embedded in RF of 802.15.4. It gives the authority to user to control the remote region like increasing or decreasing the temperature, on or off the light etc.

In paper [59] they give the systematic review how the user can control their devices, for this OSGi based architecture was established for heterogeneous devices with API that gives variety of applications, the OSGi is responsible for communication between devices.

The authors [61] proposed the Ethernet cloud for the smart home environment as basic connectivity interoperability. Cloud connectivity comes with its own challenges in perspective of security and privacy [70]. They focused on the SOAP technology which is a basic key as translator between heterogeneous devices for interoperability [61]. They proposed the smart gateway for interoperability in smart home appliances. And they provided the cloud based server which will collect the data of all homes. They used Python API for interface between sensors and actuators with smart gateway. They provide a $\mathrm{WoO}$ architecture which allows the user to easily access the objects of smart home. They use WoO architecture in different applications (smart water tank control, door security control, door security control, lights and fan control, exhaust control) [62]. They presented a methodology which consists of six steps (identification of the user need in smart home, definition of smart home functionalities, classification of smart home devices, definition of information management model, definition of intelligent rules, correlation between devices and information). They implemented their method in energy field called "washing machine scheduling service" to save energy, reduce casts, and satisfy the user [63]. They proposed an architecture of integrated middleware's for data broadcasting. For flexible profile management they proposed some APIs e.g graphics and window APIs. In case of change in existing middleware specification due to version update or correction architecture supports the updated middleware without modification [64]. They proposed a Universal Middleware Bridge (UMB) architecture that consist of UMB core and UMB adopter. They implemented there work on surveillance camera called HAVi-camera for home security purpose. Through there architecture interoperable devices are easily controlled and monitored in home network [65]. To achieve better reliability \& scalability of IOT controller based on smart home devices Liu H.B [69] proposed a home gateway grounded on ARM \& intelligent control system comprising of home network control nodes based on ZigBee. The gateway is the alteration of TCP/IP, GPRS/GSM and ZigBee protocol. It is used to establishment \& management of wireless sensor network and outside the network. Network nodes of ZigBee are responsible for making of internal network inside the smart home

\section{CONCLUSIONS}

The paper presents state of the art on interoperation among heterogeneous devices in IoT specifically in smart homes. With the growth of connected heterogeneous devices, connectivity among them is going to be a crucial need. We analyzed research articles by the communication protocol, network type, type of interoperability and year of presented work 
Table 1. Summary of reviewed literature

\begin{tabular}{lccccc}
\hline Ref & Protocol/ Technique & Network & Type of interop & Application & Year \\
\hline$[38]$ & Z Wave & HAN & BASIC & Lights, Switches. Door Lock & 2016 \\
\hline$[39]$ & RNS & LAN & Network & IGRS, iTopHome & 2014 \\
\hline$[40]$ & OpenWebNet & LAN/WIFI & Network & Switch, Actuator & 2014 \\
\hline$[41]$ & WOT & LAN & SYNTACTIC & TV, DVD & 2013 \\
\hline$[42]$ & IOT DNS & Internet WIFI & Network & Home Appliances & 2017 \\
\hline$[43]$ & SOAP & LAN & SYNTACTIC & CCTV & 2011 \\
\hline$[44]$ & CoAP, Propriety FS20 & INTERNET & SYNTACTIC & & 2012 \\
\hline$[45]$ & UPnP & & & Printer HP515x & 2011 \\
\hline$[46]$ & OHNet & & & Smart Home, Smart Grid & 2011 \\
\hline$[47]$ & Zigbee, UPnP & & Home Network & 2011 \\
\hline$[48]$ & SOAP & & & 2008 \\
\hline$[49]$ & Zigbee, JSON & HAN & BASIC & Air Conditioner, Washing Machines & 2013 \\
\hline$[50]$ & RFD & WAN & SYNTHETIC & Computer Records & 2017 \\
\hline$[51]$ & M2M, OID & WAN & NETWORK & Device Identification & 2017 \\
\hline$[52]$ & HEPA, REST & WIFI & SYNTHETIC & Plugs & 2015 \\
\hline$[53]$ & RF,ERDF,Zigbee,Bluetooth & LAN/WIFI & BASIC & Lights, Bulb & 2016 \\
\hline$[54]$ & IPv6 & WSN & NETWORK & Owen & 2016 \\
\hline$[55]$ & TCP/IP, UDP, HTTP,SOAP & HAN & NETWORK & Remotes, Laptops & 2016 \\
\hline$[56]$ & IPE, M2M,Z Wave & LAN & SYNTHETIC & Cells & 2016 \\
\hline$[57]$ & OSGi, MA & SOA & BASIC & Mobiles & 2007 \\
\hline$[58]$ & Zigbee, RF & HAN & SYNTHETIC & AC, Lights & 2010 \\
\hline$[59]$ & IPv6 & WAN & NETWORK & Machines & 2014 \\
\hline$[60]$ & OSGi, API & WAN & SYNTHETIC & Laptops & 2012 \\
\hline$[61]$ & SOAP, XML & WETWORK & Frameworks & 2008 \\
\hline & & & &
\end{tabular}

\section{ACKNOWLEDGMENT}

This study is provided by Bahria University under the supervision of Dr. Sumaira Kausar

\section{REFERENCES}

[1] Blackstock M, Lea R. (2014). IoT interoperability: A hub-based approach. In Internet of Things (IOT), 2014 International Conference on the 79-84. IEEE.

[2] Soliman M, Abiodun T, Hamouda T, Zhou J, Lung CH. (2013). Smart home: Integrating internet of things with web services and cloud computing. In 2013 IEEE 5th International Conference on Cloud Computing Technology and Science (CloudCom) 317-320. IEEE.

[3] Elkhodr M, Shahrestani S, Cheung H. (2014). A semantic obfuscation technique for the Internet of Things. In Communications Workshops (ICC), 2014 IEEE International Conference on 448-453. IEEE.

[4] Elkhodr M, Shahrestani S, Cheung H. (2016). The Internet of Things: New interoperability, management and security challenges. arXiv preprint arXiv:1604.04824.

[5] Stallings W. (2015). Foundations of modern networking: SDN, NFV, QoE, IoT, and Cloud. Addison-Wesley Professional.

[6] Atzori L, Iera A, Morabito G. (2010). The internet of things: A survey. Computer networks 54(15): 2787-2805.

[7] Gubbi J, Buyya R, Marusic S, Palaniswami M. (2013). Internet of Things (IoT): A vision, architectural elements, and future directions. Future Generation Computer Systems 29(7): 1645-1660.

[8] Jara AJ, Zamora-Izquierdo MA, Skarmeta AF. (2013). Interconnection framework for mHealth and remote monitoring based on the internet of things. IEEE Journal on Selected Areas in Communications 31(9): 47-65.
[9] Sikder AK, Acar A, Aksu H, Uluagac AS, Akkaya K, Conti M. (2018). IoT-enabled smart lighting systems for smart cities. In Computing and Communication Workshop and Conference (CCWC), 2018 IEEE 8th Annual 639-645. IEEE.

[10] Hsu AP, Lee WT, Trappey AJ, Trappey CV, Chang AC. (2015). Using system dynamics analysis for performance evaluation of IoT enabled one-stop logistic services. In Systems, Man, and Cybernetics (SMC), 2015 IEEE International Conference on 1291-1296. IEEE.

[11] Machado K, Rosário D, Cerqueira E, Loureiro AA, Neto A, de Souza JN. (2013). A routing protocol based on energy and link quality for internet of things applications. Sensors 13(2): 1942-1964.

[12] Floerkemeier C, Roduner C, Lampe M. (2007). RFID application development with the Accada middleware platform. IEEE Systems Journal 1(2): 82-94.

[13] Gubbi J, Buyya R, Marusic S, Palaniswami M. (2013). Internet of Things (IoT): A vision, architectural elements, and future directions. Future Generation Computer Systems 29(7): 1645-1660.

[14] Farhan L, Shukur ST, Alissa AE, Alrweg M, Raza U, Kharel R. (2017). A Survey on the Challenges and Opportunities of the Internet of Things (IoT). In Sensing Technology (ICST), 2017 Eleventh International Conference on 1-5. IEEE.

[15] Hussain MI. (2017). Internet of Things: Challenges and research opportunities. CSI Transactions on ICT 5(1): 87-95.

[16] Desai P, Sheth A, Anantharam P. (2015). Semantic gateway as a service architecture for iot interoperability. In Mobile Services (MS), 2015 IEEE International Conference on 313-319. IEEE.

[17] Ahsan M, Talib MR, Sarwar MU, Khan MI, Sarwar MB. (2016). Ensuring interoperability among heterogeneous devices through IoT middleware. International Journal of Computer Science and Information Security 14(4): 251. 
[18] Pandya HB, Champaneria TA. (2015). Internet of things: Survey and case studies. In Electrical, Electronics, Signals, Communication and Optimization (EESCO), 2015 International Conference on 1-6. IEEE.

[19] Fersi G. (2015). Middleware for internet of things: A study. In Distributed Computing in Sensor Systems (DCOSS), 2015 International Conference on 230-235. IEEE.

[20] Josyula SK, Gupta D. (2016). Internet of things and cloud interoperability application based on Android. In Advances in Computer Applications (ICACA), IEEE International Conference on 76-81. IEEE

[21] Tayur VM, Suchithra R. (2017). Review of interoperability approaches in application layer of Internet of Things. In Innovative Mechanisms for Industry Applications (ICIMIA), 2017 International Conference on 322-326. IEEE.

[22] Alexiou A, Raouf D, Liu CH, Zhang Y, Antón-Haro C, Aydin O, France NCSET. (2012). W3-IoT-ET 2012: WCNC 2012 workshop on internet of things enabling technologies, embracing machine-to-machine communications and beyond-Committees and welcome.

[23] Chen HC, Al Faruque MA, Chou PH. (2016). Security and privacy challenges in IoT-based machine-tomachine collaborative scenarios. In Hardware/Software Codesign and System Synthesis (CODES+ ISSS), 2016 International Conference on 1-2. IEEE.

[24] Kientopf K, Raza S, Lansing S, Güneş M. (2017). Service management platform to support service migrations for IoT smart city applications. In Personal, Indoor, and Mobile Radio Communications (PIMRC), 2017 IEEE 28th Annual International Symposium on 15. IEEE.

[25] Sun L, Wang J, Higgs R, Yang C. (2017). Analysis on the Application of Dense Storage Technology in Logistics Based on the IoT. In Computational Science and Engineering (CSE) and Embedded and Ubiquitous Computing (EUC), 2017 IEEE International Conference on 2: 214-218. IEEE.

[26] Hsu AP, Lee WT, Trappey AJ, Trappey CV, Chang AC. (2015). Using system dynamics analysis for performance evaluation of IoT enabled one-stop logistic services. In Systems, Man, and Cybernetics (SMC), 2015 IEEE International Conference on 1291-1296. IEEE.

[27] Lestari D, Wahyono ID, Fadlika I. (2017). IoT based Electrical Energy Consumption Monitoring System Prototype: Case study in G4 Building Universitas Negeri Malang. In Sustainable Information Engineering and Technology (SIET), 2017 International Conference on 342-347. IEEE.

[28] Medaglia CM, Serbanati A. (2010). An overview of privacy and security issues in the internet of things. In The Internet of Things 389-395. Springer, New York, NY.

[29] Borgia E. (2014). The Internet of Things vision: Key features, applications and open issues. Computer Communications 54: 1-31.

[30] Yong H, Pengcheng N, Fei L. (2013). Advancement and trend of internet of things in agriculture and sensing instrument. Transactions of the Chinese Society for Agricultural Machinery 44(10): 216-226.

[31] Dohr A, Modre-Opsrian R, Drobics M, Hayn D, Schreier G. (2010). The internet of things for ambient assisted living. In Information technology: New generations
(ITNG), 2010 Seventh International Conference on 804809. IEEE.

[32] Amadeo M, Campolo C, Molinaro A. (2014). Multisource data retrieval in IoT via named data networking. In Proceedings of the 1st ACM Conference on Information-Centric Networking 67-76. ACM.

[33] Amadeo M, Campolo C, Molinaro A. (2014). Multisource data retrieval in IoT via named data networking. In Proceedings of the 1st ACM Conference on Information-Centric Networking 67-76. ACM.

[34] Daubert J, Wiesmaier A, Kikiras P. (2015). A view on privacy \& trust in IoT. In Communication Workshop (ICCW), 2015 IEEE International Conference on 26652670. IEEE.

[35] Hassanalieragh M, Page A, Soyata T, Sharma G, Aktas M, Mateos G, Andreescu S. (2015). Health monitoring and management using Internet-of-Things (IoT) sensing with cloud-based processing: Opportunities and challenges. In 2015 IEEE International Conference on Services Computing (SCC) 285-292. IEEE.

[36] Stojkoska BLR, Trivodaliev KV. (2017). A review of Internet of Things for smart home: Challenges and solutions. Journal of Cleaner Production 140: 1454-1464.

[37] De Silva LC, Morikawa C, Petra IM. (2012). State of the art of smart homes. Engineering Applications of Artificial Intelligence 25(7): 1313-1321.

[38] Yassein MB, Mardini W, Khalil A. (2016). Smart homes automation using Z-wave protocol. In Engineering \& MIS (ICEMIS), International Conference on 1-6. IEEE.

[39] Yang C, Yuan B, Tian Y, Feng Z, Mao W. (2014). A smart home architecture based on resource name service. In Computational Science and Engineering (CSE), 2014 IEEE 17th International Conference on 1915-1920. IEEE

[40] Ciabattoni L, Cimini G, Grisostomi M, Ippoliti G, Longhi S. (2014). An interoperable framework for home automation design, testing and control. In Control and Automation (MED), 2014 22nd Mediterranean Conference of 1049-1054. IEEE.

[41] Kamilaris A, Pitsillides A. (2013). Towards interoperable and sustainable smart homes. In IST-Africa Conference and Exhibition (IST-Africa) 1-11. IEEE.

[42] Koo J, Kim YG. (2017). Interoperability of device identification in heterogeneous IoT platforms. In Computer Engineering Conference (ICENCO), 2017 13th International 26-29. IEEE.

[43] Perumal T, Ramli AR, Leong CY. (2011). Interoperability framework for smart home systems. IEEE Transactions on Consumer Electronics 57(4).

[44] Bergmann OK, Hillmann T, Stefanie G. (2012). A CoAP-gateway for smart homes. In Computing, Networking and Communications (ICNC), 2012 International Conference on 446-450. IEEE.

[45] El K, Charbel YD, François-Gaël O. (2011). Dynamic service adaptation for plug and play device interoperability. In Proceedings of the 7th International Conference on Network and Services Management 4655. International Federation for Information Processing.

[46] Kim JS, Kim SJ. (2011). An object-based middleware for home network supporting the interoperability among heterogeneous devices. In Consumer Electronics (ICCE), 2011 IEEE International Conference on 585-586. IEEE.

[47] Kim SJ, Seo HM, Park WC, Kim SD, Lee YS. (2011). Seamless Network Bridge for Supporting Interoperability UPnP-ZigBee. In Computers, Networks, 
Systems and Industrial Engineering (CNSI), 2011 First ACIS/JNU International Conference on 308-313. IEEE.

[48] Perumal T, Ramli AR, Leong CY, Mansor S, Samsudin K. (2008). Interoperability among heterogeneous systems in smart home environment. In Signal Image Technology and Internet Based Systems, 2008. SITIS'08. IEEE International Conference on 177-186. IEEE.

[49] Soliman M, Abiodun T, Hamouda T, Zhou J, Lung CH. (2013). Smart home: Integrating internet of things with web services and cloud computing. In 2013 IEEE 5th International Conference on Cloud Computing Technology and Science (CloudCom) 317-320. IEEE.

[50] Jabbar S, Farhan U, Shehzad K, Murad K, Kijun H. (2017). Semantic interoperability in heterogeneous IoT infrastructure for healthcare. Wireless Communications and Mobile Computing.

[51] Seo S, Kim J, Yun S, Huh J, Maeng S. (2015). HePA: hexagonal platform architecture for smart home things. In Parallel and Distributed Systems (ICPADS), 2015 IEEE 21st International Conference on 181-189. IEEE.

[52] Courreges S, Oudji S, Meghdadi V, Brauers C, Kays R. (2016). Performance and interoperability evaluation of radiofrequency home automation protocols and bluetooth low energy for smart grid and smart home applications. In Consumer Electronics (ICCE), 2016 IEEE International Conference on 391-392. IEEE.

[53] Palma L, Pernini L, Belli A, Valenti S, Maurizi L, Pierleoni P. (2016). IPv6 WSN solution for integration and interoperation between smart home and AAL systems. In Sensors Applications Symposium (SAS), 2016 IEEE 1-5. IEEE.

[54] Toschi GM, Campos LB, Cugnasca CE. (2016). An upnp architecture for interoperability in home area network. In Consumer Electronics (ISCE), 2016 IEEE International Symposium on 51-52. IEEE.

[55] Palma L, Pernini L, Belli A, Valenti S, Maurizi L, Pierleoni P. (2016). IPv6 WSN solution for integration and interoperation between smart home and AAL systems. In Sensors Applications Symposium (SAS), 2016 IEEE 1-5. IEEE.

[56] Toschi GM, Campos LB, Cugnasca CE. (2016). An upnp architecture for interoperability in home area network. In Consumer Electronics (ISCE), 2016 IEEE International Symposium on 51-52. IEEE.

[57] An J, Hwang J, Song J. (2016). Interworking technique and architecture for connecting LAN IoT devices towards standardized IoT service layer platform. In Consumer Electronics, 2016 IEEE 5th Global Conference on 1-2. IEEE.

[58] Wu CL, Liao CF, Fu LC. (2007). Service-oriented smarthome architecture based on OSGi and mobile-agent technology. IEEE Transactions on Systems, Man, and
Cybernetics, Part C (Applications and Reviews) 37(2): 193-205.

[59] Han DM, Lim JH. (2010). Smart home energy management system using IEEE 802.15. 4 and zigbee. IEEE Transactions on Consumer Electronics 56(3): 1403-1410.

[60] Xiao G, Guo J, Da XL, Gong Z. (2014). User interoperability with heterogeneous IoT devices through transformation. IEEE Trans. Industrial Informatics 10(2): 1486-1496.

[61] Kim JE, Boulos G, Yackovich J, Barth T, Beckel C, Mosse D. (2012). Seamless integration of heterogeneous devices and access control in smart homes. In Intelligent Environments (IE), 2012 8th International Conference on 206-213. IEEE.

[62] Leong CY, Ramli AR, Perumal T. (2009). A rule-based framework for heterogeneous subsystems management in smart home environment. IEEE Transactions on Consumer Electronics 55(3).

[63] Perumal T, Ramli AR, Leong CY, Mansor S, Samsudin K. (2008). Interoperability for smart home environment using web services. International Journal of Smart Home 2(4): 1-16.

[64] Iqbal A, Ullah F, Anwar H, Kwak KS, Imran M, Jamal W, ur Rahman A. (2018). Interoperable Internet-ofThings platform for smart home system using Web-ofObjects and cloud. Sustainable Cities and Society 38: 636-646.

[65] Capitanelli A, Papetti A, Peruzzini M, Germani M. (2014). A smart home information management model for device interoperability simulation. Procedia CIRP 21: 64-69.

[66] Song HY, Park J. (2006). Design of an interoperable middleware architecture for digital data broadcasting. IEEE Transactions on Consumer Electronics 52(4).

[67] Moon KD, Lee YH, Lee CE, Son YS. (2005). Design of a universal middleware bridge for device interoperability in heterogeneous home network middleware. IEEE Transactions on Consumer Electronics 51(1): 314-318.

[68] Kim JE, Barth T, Boulos G, Yackovich J, Beckel C, Mosse D. (2017). Seamless integration of heterogeneous devices and access control in smart homes and its evaluation. Intelligent Buildings International 9(1): 2339.

[69] HB L, Ding XK, Wang T. (2016). Research and implementation of smart home system based on ARM and ZigBee. Review of Computere Engineering Studies 3(4): 86-89. https://doi.org/10.18280/rces.030402

[70] Gupta ASB, Thakur SS. (2017). Cloud computing: its characteristics, security issues and challenges. Review of Computere Engineering Studies 4(2): 76-81. https://doi.org/10.18280/rces.040207 